\title{
Population Screening Contribution in the Management of Hypertension in Koudougou
}

\author{
Jonas Koudougou Kologo 1,2, Aristide Relwendé Yaméogo3 ${ }^{3}$ Boukary Ouedraogo ${ }^{4,5}$, \\ André Arthur Seghda', Joel Bamouni ${ }^{7}$, Germain D. Mandi, Georges R. C. Millogo ${ }^{1,2}$, Patrice Zabsonre ${ }^{1,2}$
}

${ }^{1}$ Department of Cardiology, Yalgado Ouédraogo Teaching Hospital, Ouagadougou, Burkina Faso

${ }^{2}$ Training Unit of Science and Research of Health, University of Ouagadougou, Ouagadougou, Burkina Faso

${ }^{3}$ Department of Medicine, Regional Hospital Koudougou, Ouagadougou, Burkina Faso

${ }^{4}$ Informatics and Telehealth Department, Ouagadougou, Burkina Faso

${ }^{5}$ University of Aix Marseille, Marseille, France

${ }^{6}$ Department of Medicine, Regional Hospital Gaoua, Gaoua, Burkina Faso

${ }^{7}$ Department of Medicine, Regional Hospital Ouahigouya, Ouahigouya, Burkina Faso

${ }^{8}$ Department of Medicine, Regional Hospital Tenkodogo, Tenkodogo, Burkina Faso

Email: yraristide@hotmail.fr

How to cite this paper: Kologo, J.K., Yaméogo, A.R., Ouedraogo, B., Seghda, A.A., Bamouni, J., Mandi, G.D., Millogo, G.R.C. and Zabsonre, P. (2016) Population Screening Contribution in the Management of Hypertension in Koudougou. Open Access Library Journal, 3: e3202.

http://dx.doi.org/10.4236/oalib.1103202

Received: November 5, 2016

Accepted: December 11, 2016

Published: December 14, 2016

Copyright $\odot 2016$ by authors and Open Access Library Inc.

This work is licensed under the Creative Commons Attribution International

License (CC BY 4.0).

http://creativecommons.org/licenses/by/4.0/

(c) (i) Open Access

\begin{abstract}
Hypertension, chronic and silent disease, is a public health problem. The objective of this survey was to assess the prevalence of hypertension in population in the city of Koudougou. This deals with a population survey held in one day consisting of controlling blood pressure and glycaemia among patients having values above the normal ones. All volunteering patients were included in the study. We screened $497 \mathrm{pa}$ tients during the survey. The average age of patients was $36 \pm 12.4$ years with extreme of 18 and 75 years. The sex ratio was 1.1. The average systolic blood pressure was $118 \pm 21.5 \mathrm{mmHg}$ with extreme of 90 and 200 and the average diastolic blood pressure was $70.8 \pm 11 \mathrm{mmHg}$ with extreme of 50 and 100 . The frequency of patients suffering from hypertension was $21.6 \%$ and that of the diabetic patients was $19 \%$. The average age of patients suffering from hypertension was $43.9 \pm 14$ years against $37.5 \pm 12.8$ years for patients suffering from diabetes. During the previous year, $49 \%$ $(\mathrm{n}=244)$ had controlled their blood pressure against $51 \%$ of cases who controlled theirs during a consultation. $16.3 \%$ of patients had their blood sugar controlled ( $\mathrm{n}=$ 81) against $43.4 \%$ who had theirs controlled during a consultation. Hypertension is an under-diagnosed disease despite the available diagnostic tools such as self-measurement. Screening programs should be set up to establish early diagnosis of high blood pressure.
\end{abstract}

Subject Areas

Cardiology, Epidemiology 


\section{Keywords}

Hypertension, High Blood Pressure, Diabetes, Screening, Koudougou, Burkina Faso

\section{Introduction}

High blood pressure is a real public health concern. Indeed, it is a chronic and silent disease affecting the noble organs (such as the kidney, heart, and brain). However, patients are under-diagnosed and most often diagnosed during complications within our context [1] [2] [3]. High blood pressure is a cardiovascular disease which considerably impairs the patient's life quality and reduces life expectancy if no efficient therapy is taken on due time [4]. The only way to determine the presence of hypertension is by measuring one's blood pressure. High blood pressure is prevalent in every community. It affects the rich and the poor, the young and the old, men and women, urban and rural populations, and the educated and illiterate alike. Reports from many nations have shown that more than $50 \%$ of the affected population, in virtually every in country, is not aware of their high blood pressure status [5]. If a person is at least aware of his or her elevated blood pressure, some actions can be taken to lower blood pressure and prevent further consequences such as heart attack, stroke or kidney failure. Screening is an efficient and affordable means of diagnosis. This survey aims at assessing the prevalence of high blood pressure among the population from the town of Koudougou.

\section{Methodology}

This dealt with a screening conducted among populations on June 6, 2015 as part of the commemoration of the international day of the fight against high blood pressure in Koudougou, a town located in the Center-West region of Burkina Faso. The population was informed through radio releases and displays throughout the town.

The commune of Koudougou is located in the Center West region of Burkina Faso within the province of Boulkiemdé at $2^{\circ} 21^{\prime} 51^{\prime \prime}$ longitude West and $12^{\circ} 15^{\prime} 3^{\prime \prime}$ latitude north. It is located $100 \mathrm{~km}$ away from the West of Ouagadougou in the central plateau and $282 \mathrm{~km}$ away from Bobo. This town is linked up to Ouagadougou the capital through the national paved road $\mathrm{N}^{\circ} 14$ by $40 \mathrm{~km}$ and through the National road $\mathrm{N}^{\circ} 1$ by $60 \mathrm{~km}$. The railways linking Ouagadougou to Abidjan also connects the commune of Koudougou to Ouagadougou and Bobo. This commune covered an estimate area of 272 $\mathrm{km}^{2}$ and counts ten (10) administrative areas. The urban agglomeration spreads over $7 \mathrm{~km}$ from East to West on both sides of the railway and holds four (4) functions on the administrative level. In addition to its urban commune status, it is the county town of the Center West region, of the province of Boulkiemdé and Koudougou Department. Since Burkina Faso has been thoroughly divided into communes, the municipal boundaries now extend to the limits of Koudougou Department. The commune new area is estimated at $580 \mathrm{~km}^{2}$ with a population amounting to 91,981 inhabitants. 
A questionnaire has been applied during an interview semi-guided by the surveyors (doctors) and after getting the consent of the patients who came for screening. This questionnaire included socio-demographic data, the patients 'medical history, their habits and lifestyle, their habits regarding blood pressure measurement, weight and glycaemia control, and sport practice. It was a systematic screening, so the number of patient was determined by the end of the activity.

After a 15 minutes rest, the blood pressure was measured through an electronic blood pressure monitor $\mathrm{OMRON}^{\bowtie}$ HEM-7113 Intelli Sense. High blood pressure was taken twice within a lapse of five minutes. Capillary glycaemia was controlled through a saccharometer of the brand ACCUCHECK ${ }^{\oplus}$; weight was taken through scales of the brand name SECA ${ }^{\oplus}$. Constants were taken by nurses trained for this purpose.

After taking these constants, a discussion was held between patients and doctors; advice was given according the patient's risk factors. Patients who had a severe blood pressure (systolic blood pressure $\geq 180 \mathrm{mmHg}$ and/or diastolic blood pressure $\geq 110$ $\mathrm{mmHg}$ ) [6] were immediately treated. As for the other cases (systolic blood pressure $\geq$ $140 \mathrm{mmHg}$ and/or diastolic blood pressure $\geq 90 \mathrm{mmHg}$ ), the patients were met a week later to the cardiologist's to confirm or infirm the persistence of high blood pressure. As for the patients whose glycaemia was $\geq 7 \mathrm{mmol}$, a plasma glucose taken on an empty stomach was conducted one week later to confirm diabetes diagnosis. The settled way of life was defined by the lack of sport practice during a minimum of thirty minutes per day or for two hours thirty minutes per week.

Data were analyzed through the software EPI INFO version 7. ANOVA test have been used as statistical test. The resulting signification threshold was $p<0.05$.

The health ministry has given authorization for this screening. Oral consent of patient was obtained and data was anonymized before analyzation.

\section{Results}

\subsection{Socio-Demographic and Medical Characteristics of the Population}

497 patients were screened during the survey. Patients' average age was estimated at $36 \pm 12.4$ with extremes reaching 18 and 75 years. Sex ratio was estimated at 1.1 with $52.4 \%$ (260) of men and $55.4 \%$ of patients were married. Tables $1-3$ display the distribution of the socio-demographic characteristics and medical history of the population.

Table 1. Marital status of 497 screened patients.

\begin{tabular}{ccc}
\hline & Frequency & Percentage (\%) \\
\hline Unmarried & 192 & 38.7 \\
Divorced & 08 & 01.6 \\
Widower & 21 & 04.3 \\
Married & 276 & 55.4 \\
Total & 497 & 100 \\
\hline
\end{tabular}


Table 2. Age range of 497 screened patients.

\begin{tabular}{ccc}
\hline & Frequency & Percentage \% \\
\hline 25 & 89 & 17.9 \\
$25-35$ & 204 & 41.0 \\
$35-45$ & 102 & 20.5 \\
$45-55$ & 58 & 11.6 \\
$55-65$ & 29 & 05.8 \\
$>65$ & 15 & 03.1 \\
Total & 497 & 100 \\
\hline
\end{tabular}

Table 3. Personal and family medical history of 497 screened patients.

\begin{tabular}{ccc}
\hline & Frequency & Percentage (\%) \\
\hline Personal history & 39 & 16.5 \\
Oral oestrogen-progesterone used & 16 & 03.2 \\
Obesity & 244 & 49.0 \\
Sedentarity & 47 & 09.5 \\
Smoking & 45 & 09.0 \\
Hypertension & 236 & 47.4 \\
Alcohol & 18 & 03.7 \\
Diabetes & & \\
Family history & & 01.1 \\
Stroke & 05 & 01.6 \\
Diabetes & 08 & 05.3 \\
Hypertension & 26 & \\
\hline
\end{tabular}

The average systolic blood pressure was estimated at $118 \pm 21.5 \mathrm{mmHg}$ with extremes reaching 90 and 200; the average diastolic blood pressure was $70.8 \pm 11 \mathrm{mmHg}$ with extremes of 50 and 100. The average systolic blood pressure of women reached 115 $\pm 22.8 \mathrm{mmHg}$ with extremes of 90 and 200; that of men was estimated at $120.9 \pm 20$ $\mathrm{mmHg}$ with extremes reaching 110 and 180 . The systolic blood pressure of men was statistically higher than women's $(\mathrm{p}=0.0005)$. The average diastolic blood pressure of women was estimated at $71.8 \pm 11.6 \mathrm{mmHg}$ with extremes reaching 50 and 100 ; that of men was $70.6 \pm 10 \mathrm{mmHg}$ with extremes reaching 50 and 90 . There was no difference between women's and men's diastolic blood pressure $(\mathrm{p}=0.7413)$. The average body mass index was estimated at $23.7 \pm 4.2 \mathrm{~kg} / \mathrm{m}^{2}$ with extremes reaching 13.4 and 38.6 . The average body mass index of men was estimated at $23.1 \pm 3.4 \mathrm{~kg} / \mathrm{m}^{2}$ with extremes reaching 14.9 and 38.4; that of women was $24.3 \pm 5 \mathrm{~kg} / \mathrm{m}^{2}$ with extremes of 13.4 and 38.7. There was no difference between women's and men's body mass of index ( $p>$ 0.05). Table 4 displays the distribution of the population's body mass index. 
Table 4. Body mass index of 497 screened patients.

\begin{tabular}{ccc}
\hline & Frequency & Percentage (\%) \\
\hline$\leq 18$ (underweight) & 18 & 03.7 \\
$18-25$ (normal weight) & 317 & 63.7 \\
$25-30$ (overweight) & 125 & 25.2 \\
$>30$ (obesity) & 37 & 07.4 \\
\hline
\end{tabular}

\subsection{Clinical Characteristics of Patients Suffering from High Blood Pressure and Diabetes}

Nine percent $(\mathrm{n}=45)$ of cases had a previous high blood pressure medical history and $3.7 \%(\mathrm{n}=18)$ had diabetes history. The frequency of patients suffering from high blood pressure was estimated at $21.6 \%(\mathrm{n}=107)$ including patients having a previous medical history of high blood pressure. The frequency of new cases of high blood pressure was estimated at $13.7 \%(\mathrm{n}=62, \mathrm{~N}=452)$. The frequency of new cases of persons suffering from diabetes was $19 \%(\mathrm{n}=95)$ including patients having previous diabetes medical history. The frequency of new diabetes cases was estimated at $16.1 \%(\mathrm{n}=77, \mathrm{~N}$ $=479)$. Diabetes was associated to high blood pressure in $34.1 \%$ of cases $(n=37)$. The average age of patients suffering from high blood pressure was estimated at $43.9 \pm 14$ years with extremes reaching 22 and 75 against an average age of $33.7 \pm 11$ years with extremes of 18 and 75 among the patients not suffering from high blood pressure ( $p<$ $0.001)$. The average age of diabetic patients was $37.5 \pm 12.8$ years with extremes reaching 18 and 75 against an average age of $35.5 \pm 12.3$ years with extremes of 18 and 75 (p $=0.3269)$ for non-diabetic patients. The sex ratio of patients suffering from high blood pressure was 1.7 against 1.1 for patients suffering from diabetes. Table 5 displays the clinical characteristics of patients suffering from high blood pressure and diabetes.

\subsection{Controlling Weight, Glycaemia and Blood Pressure}

During the previous year, $49 \%(\mathrm{n}=244)$ were able to control their blood pressure and those who controlled theirs during a consultation represented $51 \% .16 .3 \%$ of patients could control their glycaemia $(n=81)$ against $43.4 \%$ who controlled theirs during a consultation. Throughout their life, 30.5\% $(\mathrm{n}=152)$ have been controlling their glycaemia against $64.2 \%(n=319)$ who have been controlled their weight. Tables 6-8 show the distribution of patients according to weight, glycaemia and blood pressure check up.

\section{Discussion}

The weakness of this survey was the lack of diagnosis of the masked high blood pressure. Furthermore, as patients were volunteers, the selection of patients could have been shuffled.

In our survey, high blood pressure frequency was estimated at $21.6 \%$. The studies conducted by Niakara in 2003 and 2007 respectively showed a prevalence of $23 \%$ and 
Table 5. Characteristics of patients screened for hypertension $(n=107)$ and diabetes $(n=95)$.

\begin{tabular}{ccccc}
\hline & \multicolumn{2}{c}{ Hypertension } & \multicolumn{2}{c}{ Diabetes } \\
\cline { 2 - 5 } Sex & Frequency & Percentage (\%) & Frequency & Percentage (\%) \\
Men & 67 & 62.5 & 56 & 58.8 \\
Women & 40 & 37.5 & 39 & 47.2 \\
Body mass index & & & & \\
$\leq 18$ (underweight) & - & - & 03 & 02.8 \\
$18-25$ (normal weight) & 52 & 48.8 & 58 & 61.1 \\
$25-30$ (overweight) & 42 & 39.0 & 26 & 27.8 \\
$>30$ (obesity) & 13 & 12.2 & 08 & 08.3 \\
Age range (years) & & & & \\
$\leq 25$ & 10 & 09.8 & 16 & 16.7 \\
$25-35$ & 18 & 17.1 & 29 & 30.6 \\
$35-45$ & 34 & 31.7 & 32 & 33.3 \\
$45-55$ & 21 & 19.5 & 10 & 11.1 \\
$55-65$ & 16 & 14.6 & 05 & 05.6 \\
$>65$ & 08 & 07.3 & 03 & 02.8 \\
\hline
\end{tabular}

Table 6. Reasons for weight check up during the last year and the life of the 497 screened patients.

\begin{tabular}{ccccc}
\hline & \multicolumn{2}{c}{ Last year } & \multicolumn{2}{c}{ During the life } \\
\cline { 2 - 5 } & Frequency & Percentage (\%) & Frequency & Percentage (\%) \\
\hline Weight & 240 & 48.4 & 319 & 64.2 \\
Reasons for weight check up & & & & \\
Consultation & 123 & 51.0 & 165 & 51.6 \\
Curiosity & 76 & 31.7 & 56 & 17.5 \\
Pregnancy & - & - & 15 & 04.8 \\
Diseases & 26 & 10.9 & 43 & 13.5 \\
Blood donation & 08 & 03.3 & 02 & 00.8 \\
Check up & 07 & 02.9 & 38 & 11.8 \\
\hline
\end{tabular}

Table 7. Reasons for glycaemia check up during the last year and the life of the 497 screened patients.

\begin{tabular}{ccccc}
\hline & \multicolumn{2}{c}{ Last year } & \multicolumn{2}{c}{ During the life } \\
\cline { 2 - 5 } & Frequency & Percentage (\%) & Frequency & Percentage (\%) \\
\hline Glycaemia & 81 & 16.3 & 152 & 30.5 \\
Reasons for glycaemia check up & & & & \\
Consultation & 35 & 43.4 & 87 & 56.9 \\
Curiosity & 06 & 06.7 & 05 & 03.5 \\
Pregnancy & & - & 05 & 03.4 \\
Blood donation & & - & & - \\
Disease & 35 & 43.3 & 26 & 17.2 \\
Check up & 05 & 06.3 & 29 & 19.0 \\
\hline
\end{tabular}


Table 8. Reasons for blood pressure check up during the last year and the life of the 497 screened patients.

\begin{tabular}{ccccc}
\hline & \multicolumn{2}{c}{ Last year } & \multicolumn{2}{c}{ During the life } \\
\cline { 2 - 5 } & Frequency & Percentage (\%) & Frequency & Percentage (\%) \\
\hline $\begin{array}{c}\text { Hypertension } \\
\text { Reasons for blood pressure check up }\end{array}$ & 243 & 49.0 & 366 & 73.7 \\
Consultation & 124 & 51.0 & 168 & 46.0 \\
Curiosity & 77 & 31.7 & 20 & 05.5 \\
Pregnancy & & - & 15 & 04.2 \\
Blood donation & 08 & 03.3 & 08 & 02.1 \\
Disease & 27 & 10.9 & 69 & 18.8 \\
Check up & 07 & 02.9 & 86 & 23.4 \\
\hline
\end{tabular}

$40 \%$ [7] [8]. Millogo in his population survey found a high blood pressure prevalence of $30 \%$ [9]. This prevalence probably derives from a considerable epidemiologic transition within our towns with westernization of living conditions (settled way of life, tobacco, alcohol, very fatty foods). A sustained and expanded public education program will likely lead to improvements in the diagnosis of hypertension and, ultimately, to improvements in hypertension treatment and control [10].

Hypertension affects more people in the world than HIV or AIDS, but people are not aware of their elevated blood pressure status. Why? Is it because it is not a life-threatening condition, or because it is perceived as something benign? Consequences of high blood pressure are far-reaching, leading to extensive end-organ damage. If hypertension were to receive the same level of public or political attention as HIV, AIDS or breast cancer, awareness of high blood pressure would increase significantly [5].

It is very clear that the countries, especially the health ministries in most countries, are taking hypertension very seriously. The best outcome would be to see a drastic reduction in the prevalence of hypertension in all countries. With the continued involvement of national hypertension societies, we can anticipate a downward trend in the prevalence of hypertension to a lower level [5].

In our study, the proportion of patients who have never controlled their blood pressure, weight or glycaemia is very important. Indeed, studies have showed significant frequencies of patients who had never taken their blood pressure [9] [11] [12]. The population's ignorance and the lack of access to health centers could also be the reason for the lack of early diagnosis regarding cardiovascular diseases. In most cases, such patients only go to consultations when they reach a complicated stage [4] [13]. The lack of health program as regards cardiovascular diseases particularly for high blood pressure and its risk factors would considerably impede on the fight against this scourge. Screening could be an alternate way to improve high blood pressure management.

\section{Conclusion}

High blood pressure remains an under-diagnosed pathology despite the available diag- 
nosis means such as self-measurement and control in pharmacies. The population must be sensitized to control cardiovascular risk factors such as glycaemia, high blood pressure and weight. There is the need to implement treatment and screening programs to early diagnose high blood pressure. The implication of authorities, particularly health ministry is important for the fight against this disease.

\section{Acknowledgements}

To the "Junior Chamber International Ouaga Soleil and Koudougou" for this screening campaign which enables us to acquire statistical data.

To Drs. Bakoné Evariste and Yao Siaka for being available on the screening day.

To the paramedical staff of Koudougou CHR (Regional Hospital) for providing their support during the screening campaign.

To the Ministry of Health and local authorities from the town of Koudougou for their support to achieve this activity.

\section{Conflict of Interest}

The laboratory "Denk Pharma" agency in Burkina Faso has funded the screening campaign through the "Junior Chamber International Ouaga Soleil" and Koudougou.

\section{References}

[1] Lengani, A. and Samadoulougou, A. (1998) Primo Nephrology Consultation. Burkina Med, 2, 54-57.

[2] Parkouda, A. (2010) Cardiovascular Morbidity and Mortality in the Cardiology Department of Yalgado Ouédraogo University Hospital. Thesis Med, Université de Ouagadougou, Burkina Faso, 169 p.

[3] Yameogo, A.R., Mandi, G., Millogo, G., Samadoulougou, A. and Zabsonre, P. (2014) Assessing Causes of Death in the Cardiology Department of Yalgado Ouédraogo University Hospital. The Pan African Medical Journal, 19, 155. https://doi.org/10.11604/pamj.2014.19.155.5286

[4] Yameogo, R.A., Mandi, D.G., Yameogo, N.V., Millogo, G.R.C., Kologo, K.J., Toguyeni, B.J.Y., et al. (2014) The Super Hypertension in the Cardiology Department of Yalgado Ouédraogo University Hospital. Annales de Cardiologie et d Angéiologie, 63, 151-154. https://doi.org/10.1016/j.ancard.2014.04.010

[5] Chockalingam, A. (2007) Impact of World Hypertension Day. Canadian Journal of Cardiology, 23, 517-519.

[6] Mancia, G., Fagard, R., Narkiewicz, K., Redón, J., Zanchetti, A., Böhm, M., et al. (2013) ESH/ESC Guidelines for the Management of Arterial Hypertension: The Task Force for the Management of Arterial Hypertension of the European Society of Hypertension (ESH) and of the European Society of Cardiology (ESC). Journal of Hypertension, 31, 1281-1357.

[7] Niakara, A., Nebie, L.V.A., Zagre, N.M., Ouedraogo, N.A. and Megnigbeto, A.C. (2003) Knowledge of an Urban Population about Arterial Hypertension: Prospective Study Carried Out in Ouagadougou, Burkina Faso. Bulletin de la Société de Pathologie Exotique, 96, 219222.

[8] Niakara, A., Fournet, F., Gary, J., Harang, M., Nébié, L.V.A. and Salem, G. (2007) Hyper- 
tension, Urbanization, Social and Spatial Disparities: A Cross-Sectional Population-Based Survey in a West African Urban Environment (Ouagadougou, Burkina Faso). Transactions of the Royal Society of Tropical Medicine and Hygiene, 101, 1136-1142.

[9] Millogo, G.R.C., Yameogo, C., Samadoulougou, A., Yameogo, N., Kologo, K.J., Toguyeni, B., et al. (2015) Hypertension and Obesity: Epidemiology and Knowledge of Urban Adult Population between 24 -64 Years old of Ouagadougou (Burkina Faso). Médecine d Afrique Noire, 65, 23-30.

[10] Campbell, N.R., Petrella, R. and Kaczorowski, J. (2006) Public Education on Hypertension: A New Initiative to Improve the Prevention, Treatment and Control of Hypertension in Canada. Canadian Journal of Cardiology, 22, 599-600.

[11] Doulougou, B., Kouanda, S., Ouédraogo, G.H., Meda, B.I., Bado, A. and Zunzunegui, M.V. (2014) Awareness, Treatment, Control of Hypertension and Utilization of Health Care Services Following Screening in the North-Central Region of Burkina Faso. The Pan African Medical Journal, 19, 259. https://doi.org/10.11604/pamj.2014.19.259.4707

[12] Pires, J.E., Sebastião, Y.V., Langa, A.J. and Nery, S.V. (2013) Hypertension in Northern Angola: Prevalence, Associated Factors, Awareness, Treatment and Control. BMC Public Health, 13, 90. https://doi.org/10.1186/1471-2458-13-90

[13] Samadoulougou, A., Lengani, A., Yameogo, R., Millogo, G., Kologo, K., Toguyeni, B., et al. (2009) Malignant Hypertension: Epidemiological, Clinical and Outcomes Aspects in the Cardiology Department of Yalgado Ouédraogo University Hospital. Annales de P Université de Ouagadougou, 7, 1-22.

\section{Submit or recommend next manuscript to OALib Journal and we will provide best} service for you:

- Publication frequency: Monthly

- 9 subject areas of science, technology and medicine

- Fair and rigorous peer-review system

- Fast publication process

- Article promotion in various social networking sites (LinkedIn, Facebook, Twitter, etc.)

- Maximum dissemination of your research work

Submit Your Paper Online: Click Here to Submit

Or Contact service@oalib.com 